\title{
Characteristics of the Model of Methodological Training of a Teacher for Working in the Conditions of an Inclusive Educational Environment
}

\author{
Philipp Dementievich Rasskazov ${ }^{1, *}$, Olga Yurievna Muller ${ }^{2}$ \\ ${ }^{1}$ Department of Theory and Methods of Professional Education, BI HE KhMAO-Ugra "Surgut State University", Russia \\ ${ }^{2}$ Scientific and Methodical Department of Library, BI HE KhMAO-Ugra "Surgut State University", Russia
}

Copyright $\odot 2017$ by authors, all rights reserved. Authors agree that this article remains permanently open access under the terms of the Creative Commons Attribution License 4.0 International License

\begin{abstract}
A little amount of universities in Russia are busy in education of disabled students now. The methods were created and experience in sphere of inclusive education was gained. But mechanisms that help to create the development of the inclusive process of educational institution are absent. Teachers have problems with determination of approaches and technologies in inclusive education. Nowadays, 38 disabled students are studying in Surgut university of Khanty-Mansi region. According to results of the research of university's teachers' readiness for inclusive education, the major of teachers are not ready for the effective work with disabled students in conditions of inclusive education. The article is written for creation of the model of development of teacher's methodical readiness for the work in inclusive educational environment that includes creation of pedagogical conditions for inclusive educational environment. The university should be the resource center of constant inclusive education.
\end{abstract}

Keywords Inclusive Education, Cluster, Model, Methodical Readiness

\section{Introduction}

Today in Russia the inclusion of children with special educational needs in the educational process is dictated not only by various normative documents [1], but also by the social order to implement inclusive education. We need to create the most accessible and effective educational environment, organized with regard to the individual characteristics of students. The teacher, undoubtedly, becomes a key figure that can create and support an inclusive process. The teacher's professionalism in the conditions of an inclusive educational environment consists of the ability to perceive, hear and listen to the children themselves, as well as the ability to interact with colleagues, and work in a team.

Nowadays, 38 disabled students are studying in Surgut University. Unfortunately, the major part of teachers is not ready for the effective work with disabled students in conditions of inclusive education [2].

The research of university's teachers was held for getting objective information about readiness of teachers in the university for inclusive education [3]. According to the results of our survey, only $13 \%$ of teachers are willing to organize joint education of children with special educational needs and typical children (Figure 1). That is why the effectiveness of inclusion in education depends greatly on the specific training skills of teachers.

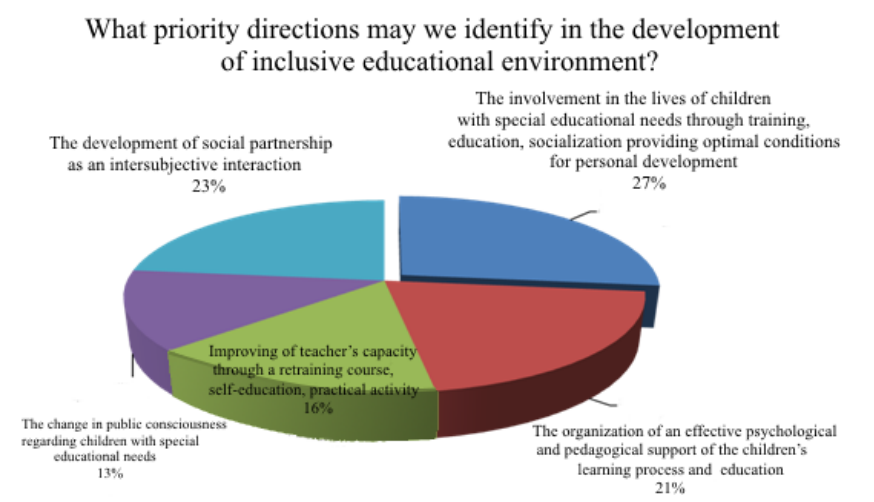

Figure 1. Priority directions in the development of inclusive educational environment

In our opinion, the result of such training should be on methodical readiness of teachers in the field of inclusive education. In the course of summarizing the results of our research, we have developed a structural model of a methodological training of a teacher for working the conditions of an inclusive educational environment.

The advantages of the structural model of methodological training of teachers are that the methodological approaches, which are its foundation. Structure and informative content 
of the components contains mechanisms, ways of children's adaptation with special educational needs. And their parents' adaption to the educational environment conditions enables multi-level support for the students with special educational needs at any educational level. It can be seen in the methodological support of teachers, student leaders of educational institutions during child's inclusion with special educational needs in the educational process along with ordinary children. The use of modern methodological foundations allows us to make adjustments to the process of creating an inclusive educational environment on the basis of scientific analysis, taking into account the synergetic concept.

\section{Materials and Methods}

Theoretical analysis of the scientific literature suggests that there are no scientific studies to develop methodological approaches to the management of methodological work in institutions of higher education [4].

Among the theorists (O.S.Anisimov, B.M. Bim-Bad, N.V. Kuzmina, A.N. Leontiev, M.K. Mamardashvili, A.K. Markov and others) there is no consensus on the substance of teaching concepts, and there is no tradition of interpretation of methodological competence of the teacher as a pedagogical category.

However, the modernization of education demands a modern teacher's willingness to solve innovative methodological problems, which involves the formation of the valuable relation to the methodical work, interest in the methodical literature; abilities to model the information in different pedagogical conditions, conduct and analyze the pedagogical experiment on the basis of special methodological knowledge.

Based on the literature review, we clarified the definition of methodological willingness of the teacher, which is the process and result of mastering the system of methodological knowledge, abilities, skills, representing a willingness to solve problems of innovative methodological problems based on the achievements of pedagogical science, advanced pedagogical experience and analysis of existing innovative pedagogical processes.

The implementation of the model is based on a methodological strategy research, in which we have identified the systematic, person-oriented, and cluster approaches.

The systematic approach used for the implementation of the structural model helps us to understand the essence of the educational process in terms of inclusion, to reveal the relationship of all the components of an inclusive educational environment. There is a possibility of modeling pedagogical process in a structured way, in conjunction with the cultural environment in accordance with the innovative requirements. Consequently, not only the model is created in accordance with the requirements of the environment, but also the existing environment requires an innovative model.
Person-oriented approach in the framework of an inclusive environment allows us to consider the problems of students' inclusion in the educational environment, integrating the following areas: a development of the personality in society, pedagogical educational impact on the social environment, the interaction of personality and environment.

For the implementation of the model, we require the cluster approach to be an effective tool for the creation and development of an inclusive educational environment in the conditions of the northern city [5]. Consequently, teacher needs to understand the general mechanism of the scientific and educational cluster and, accordingly.

According to the results of our study, 21\% of Surgut teachers believe that a support of learning process and education of children with special educational needs is an important direction in the establishment of an inclusive educational environment [6].

Due to the internal coherence of the cluster subjects, we need the mobility of its education workers, the creation and implementation of joint projects with the aim of further development of the cluster [7]. The results of the survey conducted among the city's teachers, indicate that $23 \%$ of teachers see that as a result of the development of an inclusive educational environment, the social partnership develops as inter-subjective interaction (Fig. 1).

The external links of scientific and educational cluster are determined by the level of impact of the results of the educational activities of the organizations, members of the cluster. Achieving the ultimate goal - personal development and social adaptation of persons with special educational needs can be traced. For example, through joint projects, one of which can be called the annual regional competition held by the Department of Labor and Employment of KhMAO-Ugra, socially significant programs of disability organizations, including the creation of working places and ensuring the jobs' availability for disabled people.

The results of a survey conducted that $27 \%$ of them think the main result of the development of an inclusive educational environment is the involvement of the lives of children with SEN (special educational needs) through education, training, socialization, ensuring optimal conditions for the individual's development (Fig. 2).

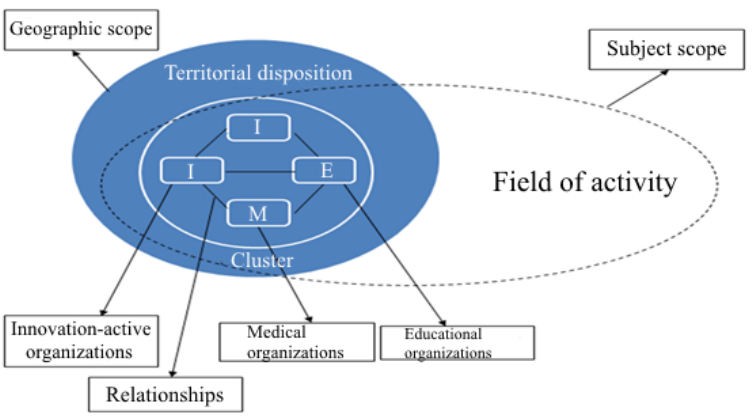

Figure 2. The main features of the scientific and educational cluster 
1. Co-operation as the main type of interaction among all educational organizations that are parts of the cluster.

2. The high level of an innovative activity involves representatives of the academic community in the educational institutions' activities that is the coordinating role of the Centre of inclusive education on the basis of Surgut State University.

It is important to take into account such aspects of competence-based approach, such as the focus on the practical result and on the development of both a child and a teacher in the process of activity for high quality implementation of structural model of teachers' training to work in the conditions of an inclusive educational environment (Figure. 3).
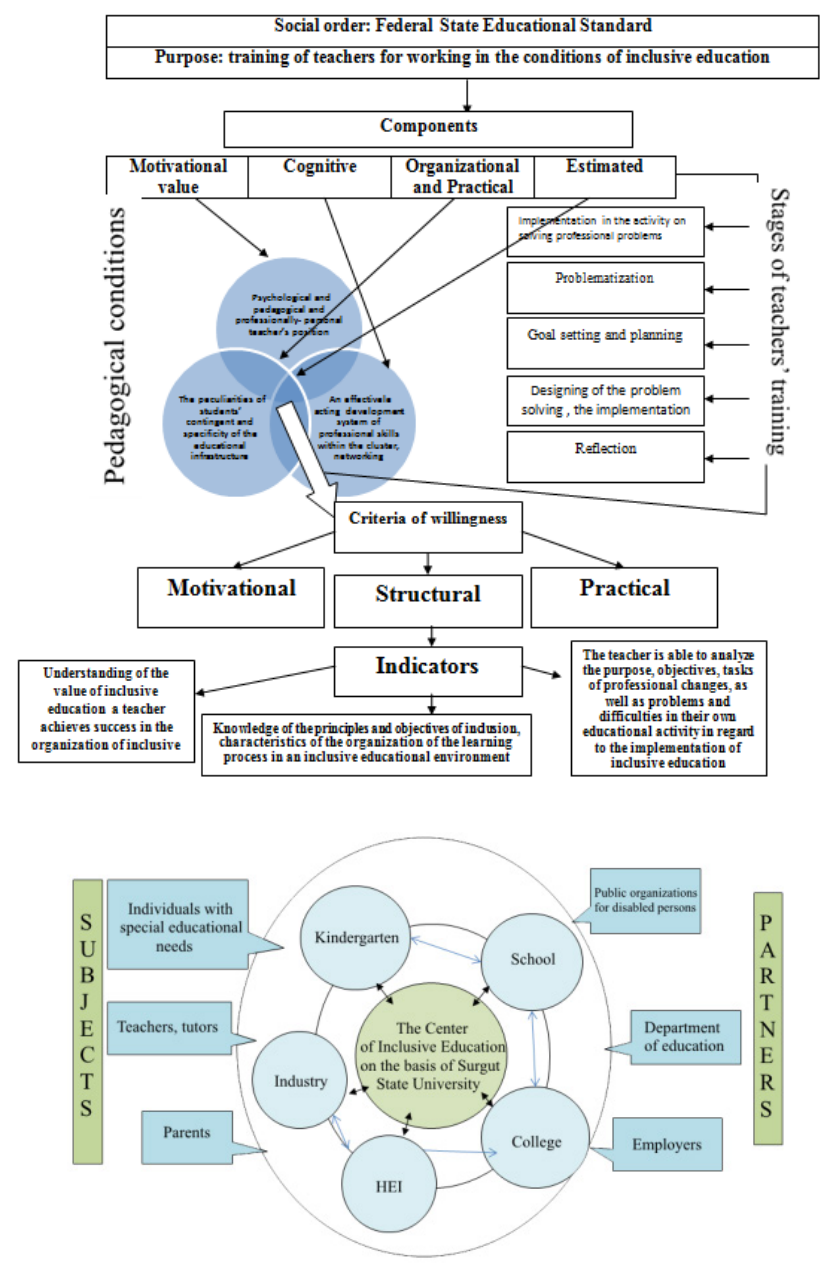

Figure 3. Structural model of training of a teacher for working in the conditions of inclusive education

As for the main teachers' competencies of educational institutions, the development of which is carried out by a modular educational program:

- $\quad$ The positive attitude of the teacher to the students with special educational needs, internal willingness to work in an inclusive educational environment;

- The knowledge and work skills in a creative teachers' team;
- $\quad$ The communicative teachers' competence in working with children with special educational needs and their parents;

- $\quad$ The ability to develop a training program for students with special educational needs;

- Possession of such technologies and methods of work with children with special educational needs, which do not require special hardware.

Based on the analysis of foreign and Russian characteristics of the content of teacher's competencies in conditions of inclusive education, we revealed the essence of methodological training of a teacher for working in the conditions of inclusive education and its components are defined as follows: motivational and evaluative, cognitive, organizational and practical evaluation. The essence of methodological training of a teacher for working in the conditions of inclusive education consists of systematic changes of teacher's knowledge and skills, aiming at finding the most effective ways of development and socialization of students with special educational needs.

Each of these model components of methodological training is presented by a teacher's training technology and includes the following stages: an immersion in a solution of professional tasks; a problematization; a goal-setting and planning; designing solutions of professional tasks and its implementation; a reflection activity.

Motivational value component:

- Understanding the value of inclusive education;

- Empathy, willingness to competent resolution of various kinds of difficulties both as with the other children and as with their parents in the process of inclusion during the academic and extracurricular activities.

Cognitive:

- Basic knowledge of didactics of special education;

- Knowledge of the basic principles of psychological and pedagogical study of children with developmental disabilities;

- Knowledge of integration models of children with disabilities;

- Knowledge of the design features of individual educational programs and activities for disabled persons in conditions of inclusive education;

- Knowledge of interactive educational methods and technologies.

Organizational and practical component:

- The ability to organize the necessary teaching style of relationships in the collective as with students with special educational needs, as well as with other children during the learning process;

- The ability to respond promptly to the specific educational needs of atypical children, to find alternative forms of communication with atypical children for the purpose of their socialization in the educational process; 
- The willingness and ability of the teacher to define certain priorities in academic and extracurricular activities for each student with special educational needs, in accordance with the educational process.

\section{Evaluative:}

- In conditions of inclusive educational environment- the ability to self- evaluation of ways of solving methodological problems;

- The ability to assess the quality of methodological support;

- The ability to assess the quality of the methodological support of educational programs.

Pedagogical conditions of effective work of the teacher in an inclusive educational environment:

1. Psychological and pedagogical, professionally personal teacher's position; Reflection of the teacher's own communicative and methodological activity; Organization of the educational process in accordance with the FSES requirements at each educational level.

Professional and personal teacher's position - is a combination of personal qualities of the teacher and the development of professional and pedagogical orientation for the effective coordination of professional activities in an inclusive educational environment. In order to implement the organizational and practical skills of a teacher, the essence of which was mentioned above, a skillful combination of his professional and personal characteristics in the communication process, an internal willingness to work with children with special educational needs are in great demand. The characteristics of a teacher in the inclusion, his distinctive features are as follows: the personality of the teacher's position, his "self-concept" defines the selecting of professional content by himself, as well as psychological and pedagogical knowledge and skills.

This is largely due to the fact that at the Center of Inclusive Education, we work with teachers who have already had work experience in an inclusive environment, and, nevertheless, it is very important to define and rank the components that determine the psychological and pedagogical, professional and personal teacher's position. You need to consider the position of the teacher to establish a dialogue with the students' social contacts with special educational needs, which is very important in the organization of person-oriented approach in training and education. Reliance on the family as the leading subject of student's socialization with special educational needs allows us to define the reserves of his development, taking into account the existing potential.

2. An effective system of professional skills' development among teachers of educational institutions, members of the scientific and educational cluster Networking

In order to create an effective system of professional skills' development, we analyzed the feasibility of using the cluster approaches in education to create an inclusive learning environment in a northern city.

As a result of the theoretical analysis of the literature, we have clarified the definition of a cluster. Cluster is a large group of institutions of scientific and educational nature, complementing each other, constantly improving their own advantages, which are linked both vertically and horizontally, with special conditions for the quality provision of educational services to persons with special educational needs.

The cluster approach requires a flexible network structures. The implementing of FSES EGE of disabled students allows to use the network form to achieve the objectives during the academic and extracurricular activities. Networking, in its turn, manifests through:

- Partnerships between higher educational institutions of the northern city, institutions of culture, sport and health, children's associations of additional education implementing the educational programs helping to meet the special educational needs of students due to disabilities;

- Development, testing, presentation to the pedagogical community of various models of realization of educational content;

- Presentation of the work results of educational institutions, which are experimental platforms.

The resource availability of each participant and a comprehensive work on their quality increase is a necessary condition for an effective networking. The results of our conducted survey showed that $16 \%$ of teachers believe that the increase of their educational potential through the coursework training, self-education, and practical activities is the result of the development of an inclusive educational environment. Thus, the professional development of the teacher is a continuous process. Its effectiveness depends primarily on the teacher. The professional skills development system may develop and coordinate the cognitive activity of the teacher. It can be said that teacher's participation in professional development concerns the whole of life.

On the one hand, the essence of a cluster requires the innovation active organizations, which are parts of it, focused on technological or organizational innovations. In our scientific and educational cluster, the Center of Inclusive Education on the basis of Surgut State University is an innovative organization. The peculiarity of the coordinating activities of the Centre is that its effective implementation will be possible with the assumption of the cooperation of educational institutions (kindergarten - school - specialized secondary educational institutions- high school). When you create a continuous educational vertical, these institutions are able to implement a systematic approach to the problem of inclusion of children with special educational needs in society.

This approach is possible through the establishment of teams, of specialists and teachers and of every educational institution, who are ready to work in the unified manner of 
integrative education. On the other hand, fulfillment of the requirements of the Federal Law "On Education in the Russian Federation" [1], the effective provision of educational services stimulates the search for different forms of cooperation with the scientific community, implementation of innovations. A high level of innovative activity involves representatives of the academic community in the activities of educational institutions.

The part of the teachers' educational needs is implemented by the teachers in a municipal education system. The activity of methodological services of educational organizations, members of the scientific and educational cluster aims:

- to study and intensify the educational needs of teachers, organize an interaction with educational institutions, institutions of additional education;

- to support teachers during the courses at the Centre of Inclusive Education on the basis of Surgut State University, suggesting a differentiated work for improving the pedagogical skills.

It is necessary to consider a professional pedagogical personality of the teacher, which is based on the conscious teacher's attitude to professional work and reflects the obvious commitment to self-improvement (N.V. Kuzmina, Ph.D. Rasskazov) in developing a teacher's professional competence. As a result of observations carried out during the implementation of competence-based approach in the networking of educational institutions, members of the scientific and educational cluster, we have identified the following pattern: it is necessary to update theoretical knowledge, practical pedagogical skills on the basis of teacher's motivation and the further development of professional skills. So, one of the necessary pedagogical conditions of teacher's training for working in the conditions of inclusive education is the development of professional skills and culture, and updating theoretical knowledge and practical skills of specialists of the education system in accordance with modern requirements to the level of qualification and the need to develop innovative methods for solving pedagogical problems. The realization of a pedagogical condition is possible during the implementation of modern educational technologies (seminars, workshops, business games, project and research activities) during the methodological work in each educational institution as a member of the cluster.

The individual development of teacher's plan is created in the framework of a person-oriented approach, taking the psychological and pedagogical data into account, including the level of value-semantic motivation; the activity level and the zone of proximal development, the training level.

3. The peculiarities of the students' contingent and the specificity of educational infrastructure: special conditions for children with special educational needs (skilled experts, educational - methodological materials, social partnership with museums, theaters, historic and cultural centers)
The peculiarities of the students' contingent at any educational level will be taken into account in the process of the teacher's training according to:

- Knowledge of the curriculum structure of the academic and extracurricular activities in order to provide students with special educational needs additional reserve time for the effective implementation of educational tasks or public orders where appropriate;

- A comprehensive assessment system of students' results with special educational needs in the academic and extracurricular activities, for this purpose the teacher should have a willingness and ability to define certain priorities in academic and extracurricular activities for each student with special educational needs, in accordance with which there is the creating of learning educational process;

- Deliberate creation of such situations for students with special educational needs in the educational process, when all students have the opportunity to exchange roles, and each student may temporarily test a new social role;

- The ability to identify the immediate and long-term educational and social prospects of students with special educational needs;

- The ability of the teacher to predict educational outcomes through the social environment, taking the special educational needs of students into account based on the strengths of the individual during the development of the educational plan, to see its reserves for compensating the gaps in knowledge.

\section{Conclusions}

Thus, the teacher's training is a system consisting of the environmental influence and the individual personality of teacher's characteristics. The whole model, presented as a set of teacher's characteristics in inclusive educational environment demonstrates ways of solving the main problem - the creation of an inclusive educational environment at different levels of education with the purpose of the fullest inclusion of students with special educational needs in a group, an educational process, in society.

\section{REFERENCES}

[1] About Education in Russian Federation: the Federal Law from 29.12.2012 number 273-FZ. .http:/ /www.sudact.ru.

[2] O.U.Muller, Ph.D.Rasskazov. Creating the conditions for inclusive education of students in Surgut State University. Educational environment today: development strategy. (Materials of the IV International scientific-practical conference. Cheboksary, December 11th. 2015, number3 (4), 213-216). Cheboksary, Russia. 
[3] O.U.Muller, Ph.D.Rasskazov. The creation of an inclusive learning environment in high educational institutes: problems and prospects. Science, education and society: Trends and Prospects of Development. (Materials Intern. Scientific-practical. Conf. Cheboksary, December 13th. 2015, .130-134). Cheboksary, Russia.

[4] N.V.Solovova. Management of methodological work of high educational institutes in the conditions of realization of innovative methodological problems: Dis...Dr.ped Science/N.V. Solovova.-Samara, 2011.-571p.
[5] Cluster policy and cluster perspectives: theory, methodology, practice. The collective emonograph. (2013) Redactors U.S.Artamonova, B.B. Khrustaleva. Penza, Russia.

[6] S.M.Kosenok, Ph.D.Rasskazov(2012).The educational systems management. Surgut, Russia.

[7] O.U.Muller, Ph.D.Rasskazov, N.A.Rotova. The cluster approach in the creation of an inclusive educational environment in a northern city. The world of science, culture, education, (number2, 2016). Gorno-Altaisk, Russia. http://elibrary.ru/contents.asp?titleid=26070. 